\title{
El color cambia con la estación
}

Sospecho que Francisco Flores tiene un corazón benigno, sin odio. Ha de ser un seguidor de Sai Baba que toma en serio sus valores humanos. Pero, por eso mismo, es un hombre peligroso. Peligroso, en primer lugar, porque a quien observa desde fuera de la cúpula de ARENA no le queda claro si Flores es más influido que influyente o viceversa. Si fuera lo primero, es preferible la claridad de un dirigente político que no deja lugar a dudas sobre el carácter poco humanitario de sus intenciones a la ambigüedad de un dirigente político que tiene buenas intenciones, pero que no las puede poner en práctica porque sus propios partidarios se lo imposibilitan. Todavía se discute si éste fue el caso de Duarte, con lo cual se discuten más sus intenciones que los resultados de su gestión presidencial.

En todo caso, la elección de Flores probablemente representa un cambio significativo en ARENA, que pasaría de una derecha tradicional - la época de D'Aubuisson- a otra que brilla con el color rosado de la vida nueva. En lugar de llevar una botella de Johnnie Walker, cinta negra, a sus fincas, la nueva generación de areneros atiende a los seminarios de Peter Drucker sobre técnicas admistrativas. De esta metamorfosis ha nacido Francisco Flores... ¿pero quién es Flores?

Para contestar esta pregunta investigué su formación académica. Flores hizo su bachillerato en la Escuela Americana de El Salvador; posee una licenciatura en ciencias políticas de Amherst College y una maestría en filosofía de The World University of America (Ojai). Realizó estudios inconclusos -es decir, que no obtuvo ningún título universitario - en Hartford University, Harvard University y Oxford, en sociología, economía y filosofía, historia y literatura, respectivamente. Las dos últimas universidades tienen fama acadé- mica mundial porque sus planes de estudio exigen no sólo una gran capacidad para absorber información cuantitativa, sino también cualitativa. Esto significa que el estudiante debe tener capacidad para analizar la información y formular sus propias ideas y argumentos. En cambio, las universidades donde Flores obtuvo sus títulos tienen un reconocimiento académico modesto - no hay que confundir Amherst College con The University of Massachusetts, donde una vez dio clases el famoso poeta estadounidense Robert Frost-.

A partir de este criterio académico, podemos afirmar que la Escuela Americana proporciona una formación en temas estadounidenses superior a la que el ciudadano estadounidense promedio tiene acceso. El estudiante, por ejemplo, puede llevar historia estadounidense a nivel universitario - esta materia es conocida como "Advanced Placement History"- En esta asignatura se desarrollan los problemas de la economía del laissez faire, en las primeras décadas de este siglo, tal como los expuso la famosa obra The Jungle, escrita por el socialista Upton Sinclair. En ella, Sinclair describió las condiciones subhumanas del trabajador y la despreocupación total por la higiene en las fábricas empacadoras de came. El impacto causado por la obra llevó al entonces presidente estadounidense, Teddy Roosevelt, a investigar la veracidad de la información de Sinclair. Cuando ésta fue confirmada por su gobierno, Roosevelt presentó y consiguió la aprobación de una ley para regular las condiciones higiénicas de estas industrias.

Con el tiempo, el trabajador luchó por el reconocimiento legal de los sindicatos y triunfó, cosa que en El Salvador no fue posible sino hasta después de una guerra civil. De esto no se habla en la Escuela Americana. Tampoco se discuten las desventajas de 
la desregulación de la economía salvadoreña, tal como lo fue la estadounidense hace más de medio siglo. En fin, las estructuras socioeconómicas de El Salvador no son comparadas con las de ningún país desarrollado. Esto, aunque fuera académicamente relevante, implicaría cuestionar un sistema económico atrasado del cual dependen los estudiantes de la Escuela Americana. Ese sistema es el que les permite conservar el privilegio de estar matriculados en ella.

Esta cuidadosa dicotomía de mundo es lo que permite la existencia de la fantasía fresa, en la cual viven los salvadoreños más educados. La fantasía consis-

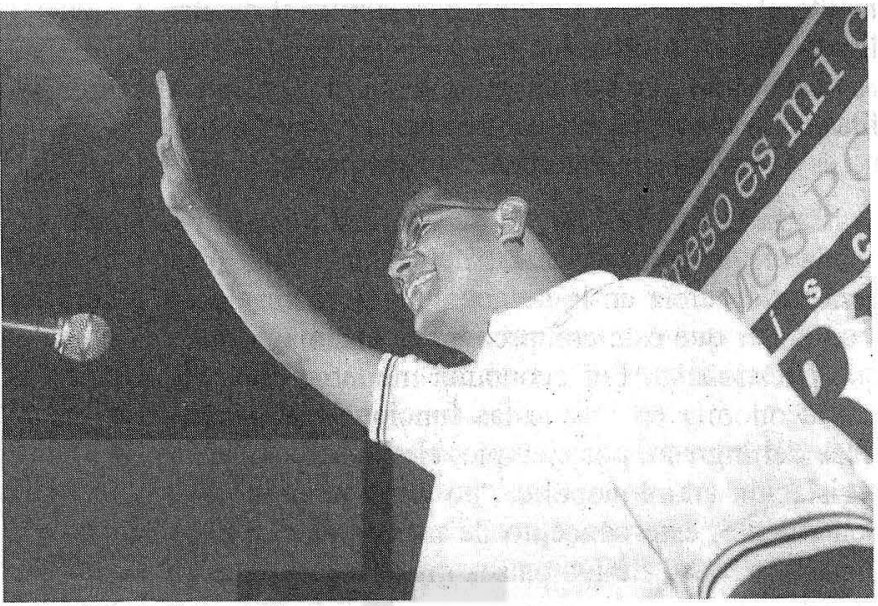
te en identificar un estilo de vida moderno con el ser moderno. Esta fantasía sostiene que la riqueza equivale a la modernidad misma; pero no se cuestiona si esa riqueza, privilegio de unos cuantos salvadoreños, es generada de una manera consistente con estructuras económicas modernas. Hasta ahora no hay evidencia, ni por su educación autóctona ni por lo que dijo durante su campaña electoral, de que Flores esté consciente de esta distinción. Su educación en el extranjero tampoco sugiere que haya caído en la cuenta de ella. Sin embargo, su extensa, si no intensa, formación en distintas ciencias sociales indica que - aunque no necesariamente con una aplicación relevante para El Salvador- Flores sí recibió una formación ideológica hasta ahora no expresada en detalle.

Por lo menos una de las instituciones de educación superior donde estudió profesa una ideología económico social concreta. Se trata de The World University (Ojai), donde obtuvo el único título de postgrado que posee. Podemos asumir, por lo tanto, que The World University (Ojai) es la institución académica que más refleja las ideas sociales de Flores. The World University (Ojai), en su Catálogo General, asegura profesar una ideología social educativa tan peculiar como sus ideas socioeconómicas. Lo primero con lo que uno se encuentra es con "(Ojai)". El lector estará de acuerdo conmigo en que colocar entre paréntesis el centro urbano donde una universidad se encuentra ubicada es algo poco corriente. Según el Catálogo General, el paréntesis en cuestión pretende mostrar que la ubicación espacial de esta universidad es secundaria o trivial, pues sus pretensiones educativas apuntan a la superación de la

regionalización de las ciencias sociales: "La Universidad del Mundo es una universidad con un currículo que trasciende el clima y la cultura, o cualquier división que separe naciones y regiones, pueblos y lugares, hasta universidades de otras universidades por prestigio o fines competitivos, y el conflicto trágico de hombre contra hombre y del hombre contra el medio ambiente" (General Catalogue, p. 8).

Tal vez por eso, The World University (Ojai) no otorga títulos en temas temporales y terrenales como sociología, economía, administración pública o ciencias políticas. Haciendo una extrapolación de la cita anterior, The World University (Ojai) es una universidad moderna atemporal, indiferente al prestigio -quizás porque tiene poco- y cuyo pénsum sociológico, científico, político trasciende el clima y la cultura - aunque es desarrollado en Ojai-. Esta extrapolación no fuera posible si, en su entusiasmo por lo universal, esta ideología no se olvidara de mencionar que todo pensador se encuentra limitado por su tiempo y el lugar que ocupa. El Catálogo General se encarga de ilustrar este punto al manifestar un anticapitalismo mediocre que ninguna dictadura de derecha toleraría: "Existe un glotón que funciona por medio de la ley de 'la oferta y la demanda', la cual ni siquiera es una ley en realidad. La ley que sí existe es la ley de la hermandad. La ley de la oferta y la demanda es simplemente egoísmo, una violación de la ley de la hermandad" (ibid., p. 7).

El misterio ideológico de la relación de Flores con ARENA empieza a florear. Si Flores acepta esta ideología, es difícil comprender cómo acepta también a ARENA. Podría estar calculando fría- 
mente el momento oportuno para abolir el capitalismo. Lo más probable es que Francisco Flores represente un cambio de generación dentro de las filas de la derecha, pero con la misma ideología - si no es que más- incoherente que sus predecesores.

Es la misma derecha la que no distingue la fachada de la estructura. La derecha de hace una generación creía en la democracia, pero sin llegar a entender que ésta comprendía el sistema político que cuestionaba. Por economía moderna entendía una economía en la que las funciones redistributivas del ingreso, por ejemplo, el sindicalismo y la legislación antimonopólica, no tenían cabida. Evidentemente, este concepto de modernidad contradice la realidad de los países más modernos en la actualidad, pero es congruente, en cambio, con la creencia de que la riqueza personal es una medida justa de la modernidad. Es así como los ricos son los modernos y los atrasados lo son por propia responsabilidad. En los países modernos, esta mentalidad fue desafiada y derrotada estructuralmente por vías legales. La posibilidad de una revolución social dentro de un sistema jurídico flexible es todavía una idea demasiado sofisticada para los salvadoreños que gozan de más privilegios educativos.

En fin, lo que detiene, en gran medida, nuestro avance social es la dicotomía ideológica que poco o nada aprendió del pasado reciente, que sigue pretendiendo que el estilo de vida que la riqueza permite es lo que define lo moderno, aun cuando la acumulación de tal riqueza implica la conservación de unas estructuras con décadas de atraso social. La versión reciclada de esta dicotomía es la dicotomía fresa. Tanto la versión de la primera generación de ARENA como la versión reciclada de Flores, por depender del atraso, deben encontrar la manera para presevar el orden establecido mientras convencen a la mayoría o al menos a sus partidarios de que luchan por el progreso. A la primera generación le preocupaba poco el convencimiento; estaba más interesada en contener las fuerzas que amenazaban con transformar las estructuras atrasadas. Sin embargo, la nueva derecha parece estar algo más preocupada por el progreso humano real, pero sin que eso implique romper con el pasado y, por supuesto, sin tomar en cuenta planteamientos sociales que pongan en peligro sus presupuestos fresa. De ahí que la nueva generación derechista necesite creer que la derecha de la primera hora no es incompatible con sus preten- siones progresistas. Esta necesidad de creer genera las ilusiones que superan las contradicciones ideológicas intergeneracionales más obvias.

El haber estudiado en The World University, a la cual le importan más sus ideales humanitarios que su prestigio, capacita a Flores para creer o querer creer que las violaciones sistemáticas de los derechos humanos protagonizadas por los fundadores de ARENA fueron simples transgresiones o "errores históricos" — pequeñas anomalías, comprensibles y excusables en cualquier caso- que no se repetirán, aun cuando las actitudes fundamentales no hayan cambiado. Por otro lado, la nueva derecha fresa, por más historia socioeconómica de los países modernos que esté obligada a leer en los colegios bilingües donde se educa, no tiene la más remota noción de que la estructura pseudoaristocrática de privilegios que está a punto de heredar es incompatible con la modernidad estructural. En este sentido, el haber estudiado en la Escuela Americana sugiere que Flores representa un fenómeno conservador a-intelectual -de hecho, "conservador a-intelectual" es una redundancia- Es por esto que la primera generación de ARENA, más terrateniente, puede coincidir con la generación fresa recién electa que viene detrás y que este partido es capaz de impulsar una política económica modernizante con rostro humano, sin que los privilegiados tengan que hacer sacrificio alguno y sin la reestructuración social que nuestros tiempos reclaman. Este es, precisamente, el plan del nuevo presidente Flores.

Francisco Flores está en lo correcto cuando afirma que el crecimiento económico actual es insuficiente. Por lo general, el crecimiento es estimulado por el descenso de las tasas de interés, puesto que ello facilita el crédito necesario para que las empresas hagan inversiones nuevas. La inyección de más dinero en la economía tiene el peligro de generar inflación. Sin embargo, existen medidas gubernamentales para combatirla. Una política impositiva progresiva, es decir, subir los impuestos de las personas naturales y jurídicas que perciben ingresos mayores, retira de la circulación el dinero inyectado en la economía sin perjudicar gran cosa a los sectores que necesitan consumir más para satisfacer sus necesidades básicas. Ambas políticas económicas son inaceptables para ARENA.

Las tasas de interés son tan elevadas porque falta competencia entre los diversos bancos del sistema. Abrir la puerta para el establecimiento de 
bancos extranjeros, en el supuesto de que esto estimulará la competencia, es ilusorio. Si hubiera competencia realmente libre, los bancos nacionales probablemente desaparecerían porque su capacidad administrativa es inferior a la de los extranjeros. El oligopolio de TACA sólo es posible gracias a la protección que el Estado salvadoreño le brinda. Esta última es la que impide que la companía aérea sea desplazada por otras empresas que ofrecen un servicio de calidad superior a un precio inferior (ver La Prensa Gráfica, 26 de marzo de 1999 , p. 35). Como muestra de lo anterior está la disputa entre TACA y COPA, la cual surgió cuando ésta protestó porque la Dirección General de Transporte Aéreo de El Salvador le retiró una aprobación ya concedida. TACA argumenta en contra de la política de cielos abiertos que cada aerolínea "opera de forma equivalente" en su país de origen. En realidad, los empresarios salvadoreños temen a la competencia libre (ver La Prensa Gráfica, 8 de febrero de 1999, que cita una encuesta de FUSADES que refleja que la preocupación principal de los empresarios es el exceso de competencia). No es aventurado inferir, entonces, que a esto se debe, en parte, el miedo a que un partido político opositor llegue a ganar unas elecciones presidenciales.

El Salvador necesita legislar la competencia libre, es decir, una legislación antimonopólica y antioligopólica, similar a la que impulsó Roosevelt hace más de medio siglo, en una situación parecida a la salvadoreña. Ahora bien, una legislación al estilo de la Sherman Trust Act resultaría insuficiente si no va acompañada por un sistema jurídico moderno. Pero esto no es posible, porque socavaría el sistema de privilegios extralegales de ARENA.

El fondo del asunto es que el Estado debe ser árbitro y no padrino. Sin árbitros el fútbol no sería fútbol. La economía salvadoreña no es y nunca ha sido una cancha libre, en la cual se destaca el más competente; es una cancha en la cual sobresale el más y mejor conectado. Por eso mismo, nunca ha sido ni es una economía moderna competitiva. El arenero es tan poco razonable que no está dispuesto a que su padrino se convierta en árbitro y redistribuya los ingresos a través de una política impositiva progresista. La reinversión cuidadosa de la recaudación fiscal - para no alimentar demasiado la inflación- por parte del Estado, aumentaría, a la larga, la capacidad de consumo del salvadoreño promedio. A su vez, esto incrementaría la capacidad de consumo de la economía a nivel macro. Una gestión creativa y ágil puede institucionalizar el progreso social a través de inversiones también sociales.

Desde la perspectiva política se suele argumentar en contra de las medidas impositivas progesivas, alegando que castiga a los más productivos. Pero este argumento no es válido en El Salvador, donde el Estado es, primordialmente, un padrino del empresario incompetente. $Y$ lo que es peor aún, la recesión actual no ofrece mucho fundamento empírico a quienes sostienen que los capitalistas son quienes mejor saben invertir en función de la modernización social y económica del país.

Haciendo un acto de justicia a la derecha salvadoreña, hay que reconocer que la historia del país tampoco ofrece asidero alguno para sostener que el Estado, prescindiendo de si es de derecha o de izquierda, sea igual o más competente para invertir en el desarrollo social real. El cambio de color de la derecha, que habría pasado del oscuro impenetrable de la primera generación al rosado gris de la siguiente, podría significar una excepción histórica. En verdad, ese cambio no es real. En el mejor de los casos lo que se puede esperar es una excepción iluminadora, pero descolorida. Iluminadora porque la ideología social de Flores da pie para creer que, a diferencia de sus predecesores, tiene buenas intenciones. Descolorida porque si considera que ARENA es compatible con sus valores humanitarios, ha de ser simultáneamente un político ingenuamente susceptible a entusiasmarse con programas cosméticos, sin fuerza para reestructurar la sociedad salvadoreña. De ahí que se pueda esperar un incremento de la actividad microfinanciera, pero jamás una disminución significativa de las tasas de interés. Por ello, el director de la Policía Nacional Civil se ensañará con el delincuente común, pero tendrá mano floja con el crimen organizado.

El problema es estructural. En efecto, las estructuras económica y política imposibilitan que la nueva derecha vaya a modificar nuestra historia circular. Circular porque ha sido dominada por las fuerzas conservadoras, que dependen del atraso social para ser progresistas. Quisiera equivocarme al predecir que los próximos cinco años de ARENA serán otros cinco años de pasado o, en el mejor de los casos, otros cinco años para consolidar 
el estancamiento social. Un estancamiento negro que se vestirá de rosado para presentarse así como un rosado gris. El no comprender cuánto desearía estar equivocado, es lo que hace que la sonrisa de
Flores, representante del resplandor de la nueva derecha fresa, sea tan peligrosa.

Andrés Roberto Centeno 